\title{
Innovative Magnetic Aggregates for the Removal of Transition Metals from Industrial Wastewater
}

\author{
Ruggiero Pesce ${ }^{1}{ }^{\circledR}$, Alessandra Accogli ${ }^{1}$, Chrysavgi Kostoula ${ }^{1}$, Juri Ilare ${ }^{1}$, Gabriele Panzeri ${ }^{1}$, \\ Caio Josè Perecin ${ }^{2}$ a and Luca Magagnin $1, * \mathbb{D}$
}

1 Dipartimento di Chimica, Materiali e Ingegneria Chimica Giulio Natta, Politecnico di Milano, 20131 Milano, Italy; ruggieromaria.pesce@polimi.it (R.P.); alessandra.accogli@polimi.it (A.A.); chrysavgi.kostoula@polimi.it (C.K.); juri.ilare@polimi.it (J.I.); gabriele.panzeri@polimi.it (G.P.)

2 São Carlos Institute of Chemistry, University of São Paulo, São Paulo 05508-060, Brazil; caio.perecin@usp.br

* Correspondence: luca.magagnin@polimi.it

Citation: Pesce, R.; Accogli, A.; Kostoula, C.; Ilare, J.; Panzeri, G.; Perecin, C.J.; Magagnin, L. Innovative Magnetic Aggregates for the Removal of Transition Metals from Industrial Wastewater. Minerals 2021, 11, 643. https://doi.org/10.3390/min11060643

Academic Editors: Ernesto Mesto and Saverio Latorrata

Received: 1 June 2021

Accepted: 11 June 2021

Published: 17 June 2021

Publisher's Note: MDPI stays neutral with regard to jurisdictional claims in published maps and institutional affiliations.

Copyright: (c) 2021 by the authors. Licensee MDPI, Basel, Switzerland. This article is an open access article distributed under the terms and conditions of the Creative Commons Attribution (CC BY) license (https:/ / creativecommons.org/licenses/by/ $4.0 /)$.

\begin{abstract}
A novel adsorbent material based on microaggregates of $\mathrm{Fe} 3 \mathrm{O} 4$ magnetic nanoparticles functionalized with succinic acid has been developed. The magnetic aggregates (MA) were characterized in terms of the size distribution (master sizer analysis), morphology (TEM), chemical structure (IR-spectroscopy and XRD), magnetic properties (VSM), and Z-Potential. The effects of various parameters such as contact time, dosage of magnetic aggregates, the amount of succinic acid on the magnetic aggregates on the adsorption capacity, as well as the efficiency of the treatment in the adsorption of two transition metals, copper $(\mathrm{Cu})$ and zinc $(\mathrm{Zn})$ from real wastewater, were investigated. The kinetic behavior was analyzed by using the Lagergren pseudo-first-order, pseudo-second-order, and Elovich and intra-particle diffusion models. Langmuir and Freundlich's models were applied to simulate the adsorption equilibrium. The magnetic aggregates reached the equilibrium condition relatively fast, within $10 \mathrm{~min}$. Magnetic aggregates with a higher amount of succinic acid in their formulation showed a higher adsorption capacity of the two metals in all the experiments. This is consistent with the adsorption mechanism mainly based on electrostatic interaction between the metal ions and the negative charges on the surface of magnetic aggregates. A higher adsorption capacity for the removal of copper compared to zinc was found. Additionally, the electrochemical characterization of the magnetic aggregates was done as a preliminary study for proposing a regeneration method of the MA along with the extraction metals adsorbed based on an electrochemical process.
\end{abstract}

Keywords: transition metals; magnetic aggregates; wastewater treatment; nanomaterials; metals remediation

\section{Introduction}

Transition metal removal from industrial wastewater is of paramount importance due to the harmful effects of heavy metals on human health and the environment. For such reasons, water treatment for the removal of heavy metals has engaged numerous applications and technologies over the last decades, although more research is required to improve such technologies. Treatment methods are classified as chemical, physical, and biological and their selection takes into consideration several features as well as their limitations [1]. The most-used methods for the removal of transition metals from industrial wastewater include adsorption, cementation, membrane filtration, electrodialysis, and photocatalysis, although the selection of the most suitable method depends on a series of parameters: cost, environmental impact, metal concentrations, and $\mathrm{pH}$ values $[1,2]$.

Two of the most common transition metals used by the electrical and the electroplating industry are copper and zinc. In this regard, it is important to consider that copper, even in small amounts, is highly toxic for humans and it has the ability to accumulate in the food chain. Despite this, copper is worth recovering from wastewater because of its high price 
and market demand [3]. Up-to-date, various methods have been employed for recovering copper ions from wastewater, including traditional methods such as co-precipitation and electrochemical processes and more alternative technologies such as membrane filtration and ion exchange technologies [3]. Interestingly, such methods pose some significant limitations to their use due to the high cost, high energy consumption, expensive equipment, and incomplete metal removal [2]. On the other hand, zinc is frequently used in industrial processes such as in the steel, batteries, and paint production chains as well as in the plating industry, which generates wastewater with a high concentration of zinc [4,5]. Despite the fact that zinc is essential for several metabolic processes, in high concentrations, it is harmful to both human health and the environment [5,6]. In the case of zinc, absorption is one of the most effective methods for removing heavy metal ions from wastewater, although there is still need for improvement in the development of absorbent materials [5].

In recent years, great effort has been dedicated to the development of magnetic nanoparticles that can efficiently capture transition metals from industrial wastewater. Several studies have demonstrated the efficiency of different types of magnetic materials in water treatment and, in particular, in the removal of toxic metal ions [7-17]. Specifically for the removal of metals, different types of MA and magnetic bead functionalized with polymers have been used [8,18-21]. However, such materials usually require a multi-step process for their production and functionalization is done after the formation of $\mathrm{Fe}_{3} \mathrm{O}_{4}$ nanoparticles $[9,19,20]$. Here, functionalized magnetic aggregates composed of magnetic nanoparticles that have been functionalized with succinic acid in a one-step process have been used in order to study the capture of copper and zinc ions from real wastewater samples. Contrary to what has been reported by Singh et al. [17], the nanoparticles in the present study form micro-sized aggregates, which, in a possible large-scale industrial application, could be handled easier with fewer health and safety and environmental concerns in respect to nano-sized particles [22,23]. Magnetic aggregates were synthesized and functionalized by co-precipitation of Fe(II) chloride and Fe(III) chloride in an alkaline solution containing succinic acid. The ferromagnetic core has superparamagnetic-like properties that can be used for the separation of the magnetic aggregates from the treated solution. Succinic acid acts both as a stabilizer and as a selective anionic coating bonded through a covalent bond and is thus selective for the metal cations used in this study. MA were characterized and tested for $\mathrm{Cu}^{2+}$ and $\mathrm{Zn}^{2+}$ removal from aqueous solutions. Important factors affecting absorption efficiency such as coating percentage and contact time as well as desorption for ion recovery were investigated. Lastly, preliminary experiments were conducted to explore the possibility to regenerate the magnetic aggregates through an electrochemical process, extracting at the same time the pollutants that can be used again as raw materials.

\section{Materials and Methods}

\subsection{Sample Preparation}

Magnetite nanoparticles and their aggregates were synthesized according to the recipe provided by Captive Systems. The magnetic aggregates were produced according to a one-step co-precipitation reaction in a basic environment following the method previously reported [24]. A solution of Fe(II) chloride (commercial grade, p.c. FER008000000, Brenntag) and Fe(III) chloride (commercial grade, p.c. FER006000000, Brenntag) in molar ratio 1:2 was prepared. According to the stoichiometry of the reaction, sodium hydroxide was dissolved in water to obtain the basic solution. Functionalized magnetic aggregates with negatively charged surfaces (Figure 1) were obtained by adding succinic acid (commercial grade, p.c. 203-740-4, Brenntag) into the basic solution. Two different percentages of succinic acid with respect to the weight of MA were used to obtain MA with 5\% w/w and $10 \%$ of the coating compared to the magnetite core. 


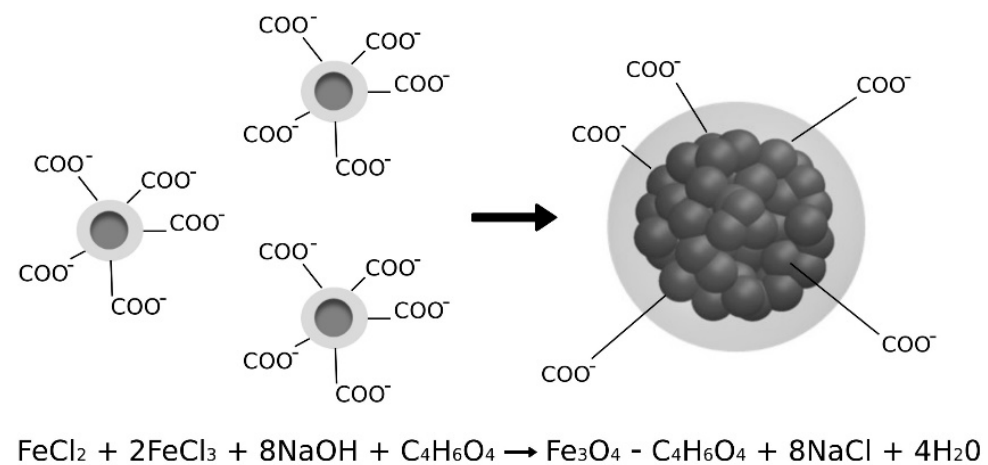

Figure 1. Formation reaction and structure of aggregated nanoparticles coated with succinic acid.

The Fe(II-III) chloride and the sodium hydroxide solutions containing succinic acid were pumped through two syringe pumps with a flow rate of $25 \mathrm{~mL} \mathrm{~min}^{-1}$, into a mixing device that guarantees a turbulent flow. The co-precipitation reaction takes place in the mixing device, resulting in the formation of magnetic aggregates of functionalized nanoparticles. The MA were collected into a beaker and then aged for $30 \mathrm{~min}$ under low stirring to stabilize the aggregates. The excess sodium hydroxide and sodium chloride produced during the co-precipitation reaction was removed through a series of washing cycles with distilled water and centrifugation (Sorvall ${ }^{\mathrm{TM}}$ ST 8 Benchtop Centrifuge, Fisher Scientific, Munich, Germany) until the $\mathrm{pH}$ of the solution resulted neutral.

\subsection{Sample Characterization}

Fourier transform infrared spectroscopy (FTIR) analysis was performed to check the effective presence of the coating on the surface of the MA with succinic acid. The measurements were done on dried MA supported on $\mathrm{HBr}$ support using an FTIR spectrophotometer (Thermo Fisher Nicolet 380, Fisher Scientific, Munich, Germany) in a wave range of 4000- $0 \mathrm{~cm}^{-1}$ with a resolution of $5 \mathrm{~cm}^{-1}$ according to the transmittance method.

A transmission scanning microscope (TEM) (PHILIPS CM200, Philips Electron Optrics) was used to determine the dimension and morphology of the produced magnetite aggregates. X-ray diffraction analysis (XRD) (Philips model PW1830. K $\alpha 1 \mathrm{Cu}=1.54058 \AA$, Fei Electron Optics Bv, Eindhoven, Netherlands) was used to define the microstructure of the oxide. The particle size distribution of the aggregates was measured using MasterSizer 3000 (Malvern Panalytical, Monza, Italy) while the Z-potential was obtained by using Zetasizer Nano ZS DLS (Malvern Panalytical, Monza, Italy). Magnetic properties were measured using VS) M (EZ9, MicroSense). B Brunauer, Emmett, and Telle analysis (BET) was used to determine the skeletal density and the specific surface area (NovaTouch, AntonPaar).

\subsection{Adsorption Test}

The synthesized MA were used to remove and recover copper ions from industrial wastewaters. The wastewaters were provided by Gaser Group, an Italian electroplating company. The first wastewater sample (sample 1) was contaminated only with copper in a concentration of $350 \mathrm{mg} / \mathrm{L}$ at pH 6.9, and the second sample (sample 2) containing both copper and zinc in a concentration of $138 \mathrm{mg} / \mathrm{L}$ and $126 \mathrm{mg} / \mathrm{L}$, respectively, at $\mathrm{pH}$ 7.2. The adsorption tests were conducted in batch mode using $100 \mathrm{~mL}$ of wastewater and adding to the sample the solution containing the MA and stirring with a magnetic stirrer. The stirring was stopped at different time points during the test (from $1 \mathrm{~min}$ to $120 \mathrm{~min}$ ) and the MA were collected on the bottom of the beaker using a neodymium magnet. The resulting solution was analyzed through Inductively Coupled Plasma Mass Spectrometry, ICP-MS, (Optima 8300, Perkin Elmer, Milan, Italy), to evaluate the residual amount of metal ions after the treatment. The effect of contact time on the efficiency of the MA in removing metal 
ions was tested. Two different amounts of MA were employed with a maximum contact time of $2 \mathrm{~h}$. The efficiency $(\eta)$ was calculated as in Equation (1):

$$
\eta=\left(C_{i}-C_{f}\right) / C_{i} \times 100
$$

where $C_{i}$ and $C_{f}$ represent the initial and the final concentration of the metal ions in the supernatant $\left(\mathrm{mg} \mathrm{L}^{-1}\right)$.

At a fixed contact time, the mass balance reported in Equation (2) was used to determine the adsorbed amount of metal ions per gram of $\mathrm{MA}\left(\mathrm{Q}, \mathrm{mg}\right.$ of metal ion $\mathrm{g}^{-1}$ of $\left.\mathrm{MA}\right)$ :

$$
\mathrm{Q}=\left[\left(\mathrm{C}_{\mathrm{i}}-\mathrm{C}_{\mathrm{f}}\right) / \mathrm{mMA}\right] \mathrm{V}
$$

where $C_{i}$ and $C_{f}$ represent the initial and the final concentration of the metal ions in the supernatant $\left(\mathrm{mg} \mathrm{L}^{-1}\right)$, mMA is the amount of MA used in the test $(\mathrm{g})$, and $\mathrm{V}$ is the volume of the sample $(\mathrm{L})$. When the adsorption process reaches the equilibrium, $\mathrm{Q}$ indicates the maximum adsorption capacity, $\mathrm{Q}_{\max }$, and $\mathrm{C}_{\mathrm{f}}$, the equilibrium concentration, $\mathrm{C}_{\mathrm{e}}$.

\subsection{Electrochemical Characterization}

Electrochemical characterization of the MA was done by a cyclic voltammetry test. A standard three-electrode setup was employed, which consisted of a platinum wire counter electrode (CE), an $\mathrm{Ag} / \mathrm{AgCl}$ reference electrode (RE), and a working electrode (WE), i.e., MA deposited on an inert substrate. The latter, a fluorine-doped tin oxide (FTO) coated glass, assured the electrical contact with the magnetite particles, deposited through dropcasting method, allowing to investigate the activity of $\mathrm{Fe}_{3} \mathrm{O}_{4}$ particles. A typical working electrode fabrication comprised the drop-casting of $20 \mu \mathrm{L}$ of an aqueous solution containing $20 \mathrm{~g} / \mathrm{L} \mathrm{Fe}_{3} \mathrm{O}_{4}$ particles onto a $1 \mathrm{~cm}^{2}$ substrate area, the geometrical area in direct contact with the electrolyte solution. The ink was dried at $40{ }^{\circ} \mathrm{C}$ on a hotplate until the complete evaporation of the solvent occurred. To limit the ohmic contribution, the reference electrode was placed in the proximity of the working electrode, allowing a proper measurement of the electrochemical signal. The voltammetric investigation was carried out in a $0.1 \mathrm{M}$ $\mathrm{NaSO}_{4}$ solution, at $\mathrm{pH}$ 5.5. Before the test, the MA were immersed in two control solutions containing zinc or copper ions, and thoroughly washed.

\section{Results and Discussion}

\subsection{MA Characterization}

The synthesis conditions selected resulted in the formation of stable micron-sized aggregates of unitary nanoparticles with an average diameter of 10-15 nm. Figure 2c,d show TEM images of MA with $10 \% w / w$ of coating. This specific geometry allows maintaining the advantages in terms of the extremely high surface area of the nanomaterials, avoiding the problem of the separation of nano-sized compounds thanks to the micron-size of the aggregates. Comparing the diffraction pattern (Figure 2a) obtained with TEM measurements to those collected with a conventional XRD apparatus (Figure 2b), it is possible to notice that only characteristic reflection peaks corresponding to pure magnetite $\left(\mathrm{Fe}_{3} \mathrm{O}_{4}\right)$ are present and not peaks belonging to other iron oxide forms such as maghemite $\left(\mathrm{Fe}_{2} \mathrm{O}_{3}\right)$.

The effective formation of the organic coating on the magnetite particles was evaluated through Fourier Transformed Infrared (FTIR) spectroscopy. The spectrum of succinic acid (Figure 3a) was taken as reference. Figure 3b shows the FTIR spectrum of the MA coating with succinic acid, where it is possible to observe the characteristic peaks of the succinic acid at about $1633 \mathrm{~cm}^{-1}$. The peak related to symmetric stretching of the carboxylate group is at $1537 \mathrm{~cm}^{-1}$ and at about $1400 \mathrm{~cm}^{-1}$ that of the $\mathrm{C}-\mathrm{H}_{2}$ scissoring. The characteristic peaks of the $\mathrm{O}-\mathrm{H}$ of carboxylic groups are present between 3000 and $3500 \mathrm{~cm}^{-1}$. The characteristic peaks of magnetite appear at 400 and $550 \mathrm{~cm}^{-1}$. The small peak at $1025 \mathrm{~cm}^{-1}$ is related to the $\mathrm{C}-\mathrm{O}$ stretch. The peak representing the $\mathrm{C}=\mathrm{O}$ bond of saturated carboxylic acids, which is usually located at $1700 \mathrm{~cm}^{-1}$, is no longer present, supporting the fact that 
the coating binds the $\mathrm{Fe}-\mathrm{O}$ of the MA through carboxylate groups. The results confirmed the effective functionalization of the magnetite surface.

a)

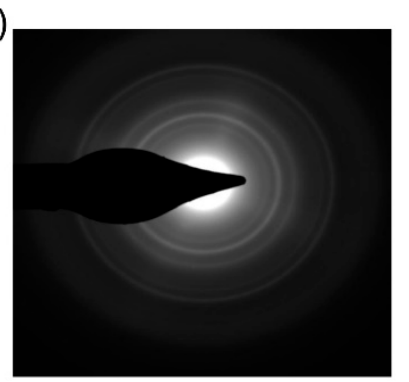

c)

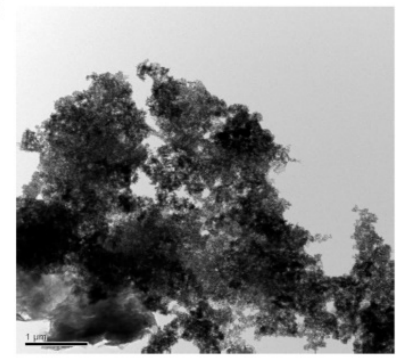

b)

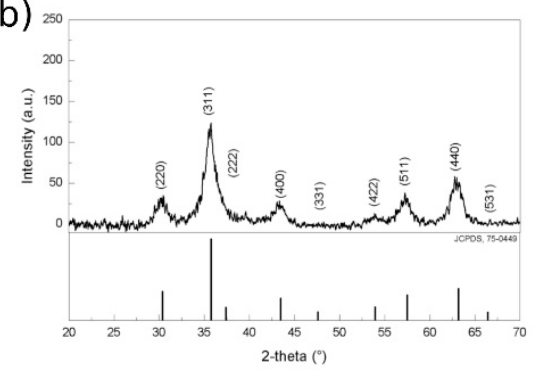

d)

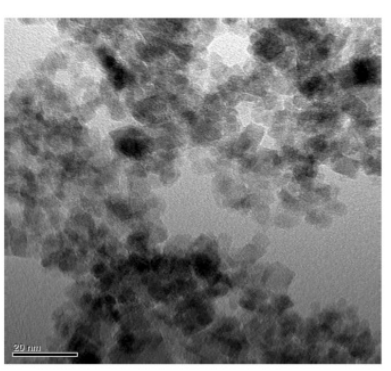

Figure 2. MA (a) TEM diffraction pattern. (b) Diffraction pattern collected with XRD apparatus for succinic-coated magnetite nano-aggregates and XRD reference pattern of $\mathrm{Fe}_{3} \mathrm{O}_{4}$ from the Joint Committee on Powder Diffraction Standards (JCPDS), no. 75-0449. (c,d) TEM images. Scale bars: $1 \mu \mathrm{m}(\mathbf{c}), 20 \mathrm{~nm}(\mathbf{d})$.
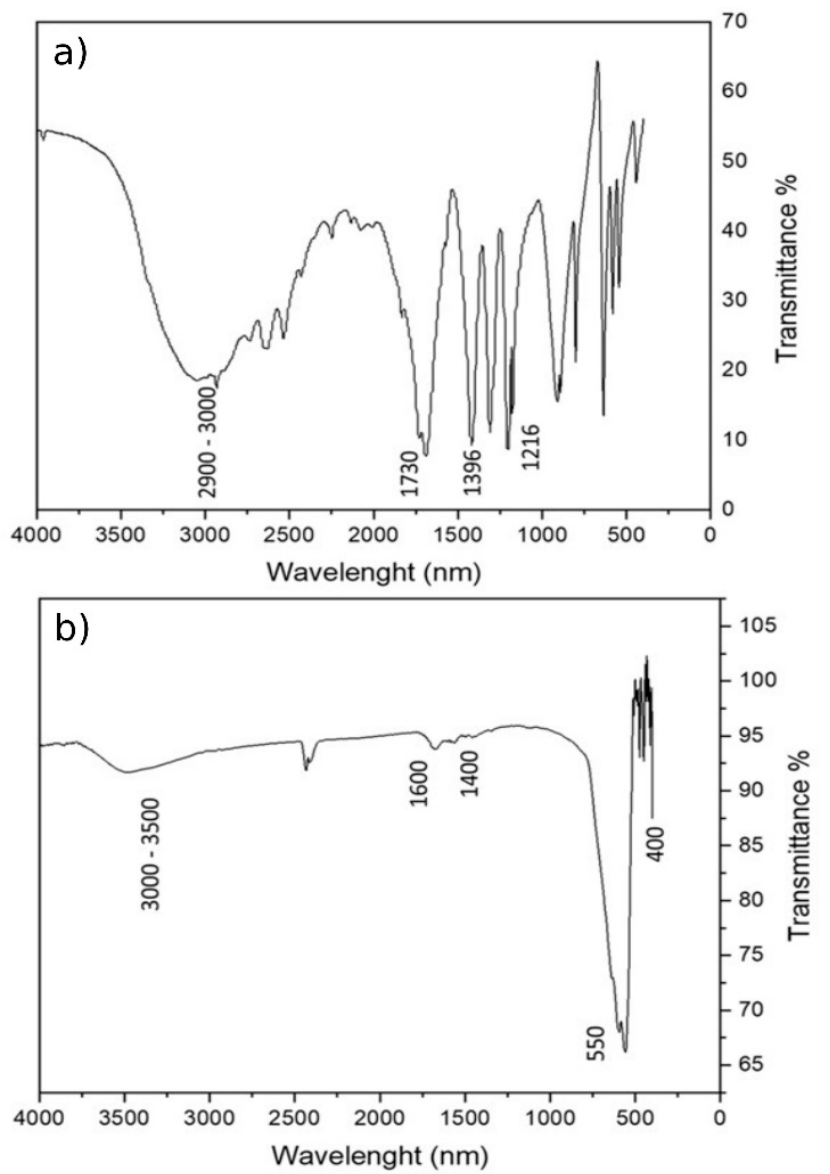

Figure 3. FTIR analysis (a) spectrum of succinic acid, and (b) MA coated with succinic acid. 
The effect of the concentration of the succinic acid on the size distribution of the coated nanoparticle aggregates was evaluated. Figure $4 \mathrm{a}, \mathrm{b}$ report the results of the analysis of the aggregates obtained with two different percentages $w / w$ of succinic acid compared to the weight of magnetite core. Using $10 \% w / w$ of succinic acid results in aggregates with an average diameter of $30 \mu \mathrm{m}$ (Figure $4 \mathrm{a}$ ). Decreasing the coating to a percentage of $5 \% w / w$ leads to aggregates with a dimension of $50 \mu \mathrm{m}$ (Figure $4 \mathrm{~b}$ ) due to the effect of the succinic acid acting as a stabilizer. The coating is expected to cover the surface of the nanoparticles, preventing aggregation. Succinic acid guarantees a negative charge on the surface of nanoparticles and this negative charge acts as a repulsive force, preventing the agglomeration $[25,26]$.
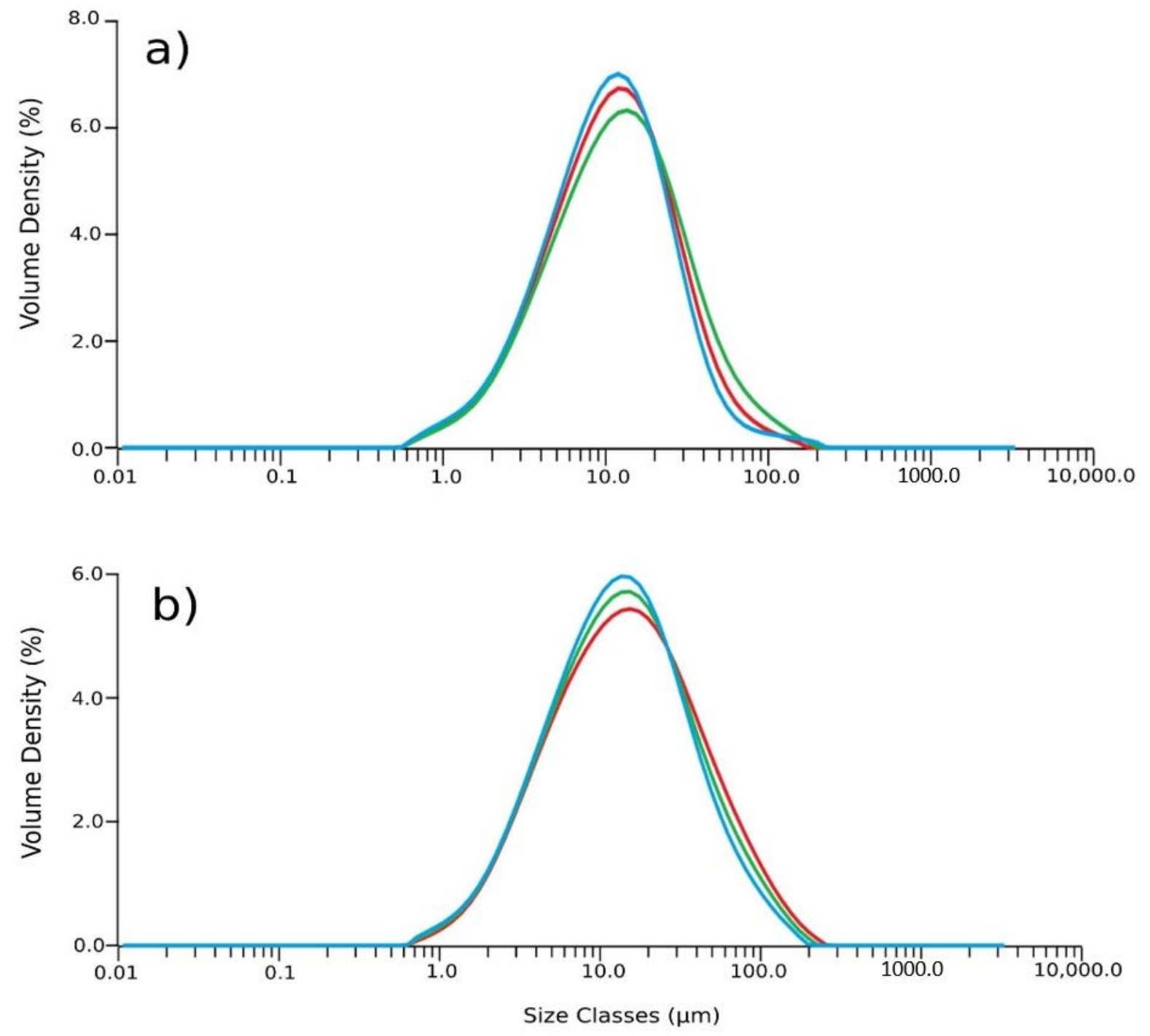

Figure 4. Particles' size distribution of aggregates with (a) $10 \% w / w$ of coating and (b) $5 \% w / w$ of coating.

MA show a good magnetic saturation (M) at room temperature and 20KOe (Figure 5a). MA with $5 \% w / w$ of coating have a $\mathrm{M}$ of $22.7 \mathrm{emu} / \mathrm{g}$, while the those with $10 \%$ of coating have an $\mathrm{M}$ of $19.5 \mathrm{emu} / \mathrm{g}$. This was expected indeed, since the MA with $10 \%$ of coating have more non-magnetic mass on them. The coercivity measured was 28.5 Oe and $37.6 \mathrm{Oe}$, respectively, for MA with $5 \%$ and $10 \%$ of coating (Figure $5 \mathrm{~b}$ ); thus, these materials have a superparamagnetic-like behavior. 

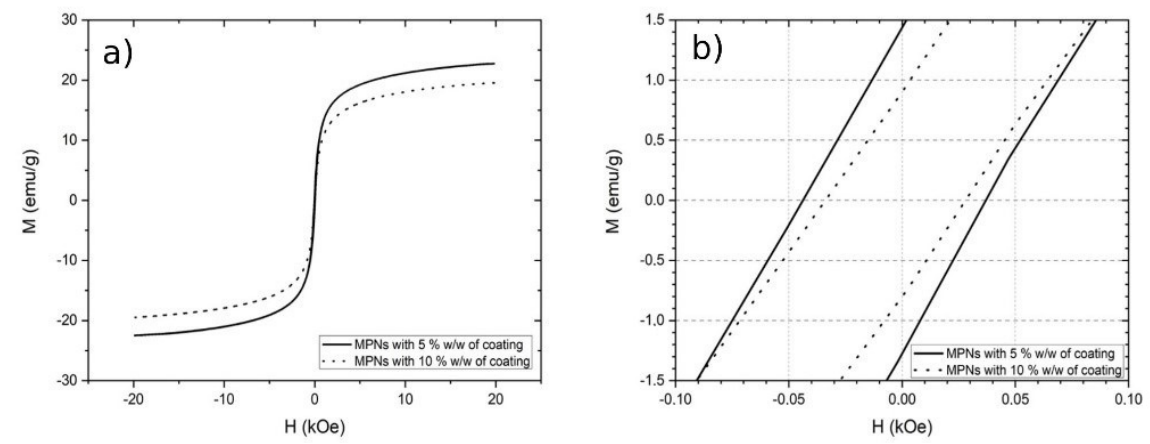

Figure 5. VSM curve of functionalized MA at room temperature. (a) Magnetic saturation, (b) coercivity behavior.

The BET surface area and the skeletal density were found to be $85.6 \mathrm{~m}^{2} \mathrm{~g}^{-1}$ and $6.24 \mathrm{~g} \mathrm{~cm}^{-3}$ for the MA with $10 \%$ of coating and $62.9 \mathrm{~m}^{2} \mathrm{~g}^{-1}$ and $4.12 \mathrm{~g} \mathrm{~cm}^{-3}$ for the MA with $5 \%$ of coating. The zeta potential at $\mathrm{pH} 7$ was $-31.3 \mathrm{mV}$ and $-21.6 \mathrm{mV}$, respectively, for the MA with $10 \%$ of coating and for the MA with $5 \%$ of coating, while the Z-potential of bare magnetite is $-0.8 \mathrm{mV}$. These results agree with the type of coating used, which provides negative charges on the surface of the particles.

\subsection{Adsorption Tests}

Experiments were carried out to establish the contact time needed to reach the adsorption equilibrium. This condition is found when the MA reach their maximum adsorption capacity and efficiency and indicates the contact time needed for performing an efficient treatment. This information is crucial for the correct design of the treatment equipment. Short contact time for reaching the equilibrium means a small size reactor and space needed, thus lower costs. The experiments were carried out in batch mode in $100 \mathrm{~mL}$ of each of the wastewater samples (sample 1 and sample 2). MA with different percentages of coating $(5-10 \% w / w)$ and a dosage of $1000 \mathrm{ppm}$ were used for the experiments that had a duration of $120 \mathrm{~min}$. Samples of treated water were taken for the ICP-MS analysis at different time points. The efficiency was measured as reported in Equation (1).

\subsubsection{Single-Ion Adsorption}

Results obtained from sample 1 measurements (containing only copper ions) show that a short contact time was sufficient to achieve the adsorption equilibrium, as explained by the adsorption mechanism considered [27]. The uptake of metal ions takes place on the surface of MA by monolayer adsorption and the contribution of limitation due to internal diffusion resistance is negligible. At a MA dosage of $1000 \mathrm{ppm}$, the maximum adsorption capacity $(\mathrm{Q})$ was reached within $10 \mathrm{~min}$ of contact time and then reached a plateau (Figure 6), indicating that the adsorption process reached the equilibrium.

It was observed, that, while the time for reaching the adsorption equilibrium is not correlated to the percentage of coating, the value of the maximum adsorption capacity depends strictly on the amount of coating used in the MA. The MA with $5 \% w / w$ of succinic acid had a maximum adsorption capacity Qmax of $122 \mathrm{mg}$ of copper $\left(\mathrm{Cu}^{2+}\right)$ for a gram of MA. Increasing the amount of coating to $10 \% w / w$, the Qmax increased to $153 \mathrm{mg}$ of copper $\left(\mathrm{Cu}^{2+}\right)$ for a gram of MA. The adsorption mechanism is driven by physio-chemical interactions, mostly represented by electrostatic attractions between the metal ions and the hydroxyl groups present on the surface of the MA. Increasing the amount of coating during the synthesis of the MA resulted in more hydroxyl functional groups available for the adsorption of metal ions; thus, the efficiency of the treatment is enhanced [28,29]. 


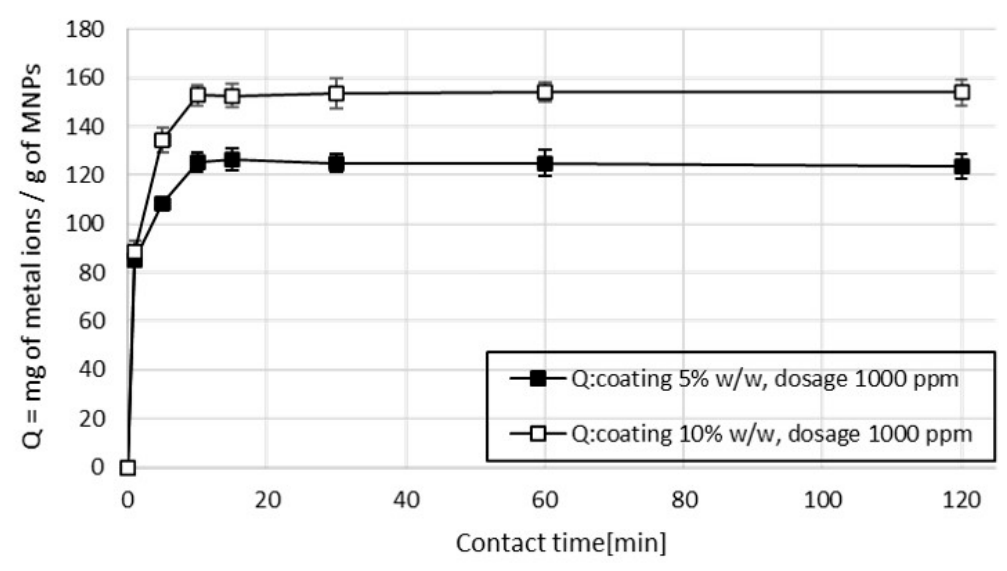

Figure 6. Effect of contact time and percentage of coating on the adsorption capacity for $\mathrm{Cu}^{2+}$, dosage 1000 ppm, pH 6.9.

The effect of the dosage of MA on the adsorption capacity of copper $\left(\mathrm{Cu}^{2+}\right)$ was studied by performing a series of batch experiments in $100 \mathrm{~mL}$ of sample 1 using MA with $5 \%$ w/w and $10 \% w / w$ of coating. Taking into consideration the results from previous experiments, it was decided to use a contact time of $30 \mathrm{~min}$ to ensure adsorption equilibrium. Figure 7 shows the behavior of the maximum adsorption capacity Qmax, calculated according to Equation (2), at increasing dosages of MA (from 100 to $1000 \mathrm{ppm}$ ). The trend of the treatment efficiency at various dosages, calculated according to Equation (1), is also reported.
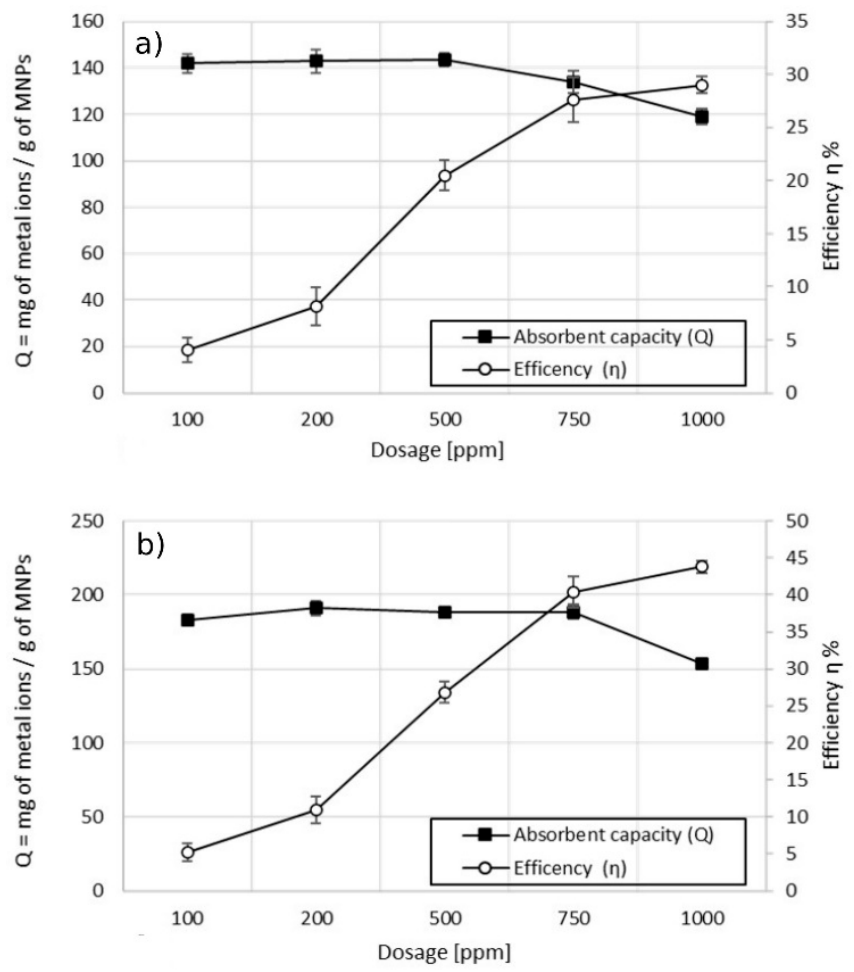

Figure 7. Effect of the dosage on adsorption capacity vs. efficiency. (a) MA with $5 \% w / w$ of coating; (b) MA with $10 \% w / w$ of the coating, $\mathrm{pH} 6.9$.

From the results obtained, an optimal dosage to optimize the maximum adsorption capacity related to the efficiency of the treatment can be defined. The ideal dosage would maximize the interactions between metal ions and adsorption sites present on the MA [30,31]. Increasing the dosage of MA led, firstly, to a linear increase of efficiency while the adsorption capacity remained constant. Further increase of the dosage led to a 
slight increase in the efficiency of the treatment, while the adsorption capacity decreased drastically. In the case of MA with $5 \% w / w$ coating (Figure $7 \mathrm{a}$ ), the maximum $\mathrm{Q}$ was $144 \mathrm{mg}$ of $\mathrm{Cu}^{2+}$ per gram of MA at a dosage of $500 \mathrm{ppm}$ with an efficiency of the treatment equal to $20 \%$. Doubling the dosage to $1000 \mathrm{ppm}$, the adsorption capacity was $30 \%$ lower while the efficiency of the treatment increased by $10 \%$. The maximum adsorption capacity, using MA with $10 \% w / w$ coating (Figure $7 \mathrm{~b}$ ), was equal to $188 \mathrm{mg}$ of $\mathrm{Cu}^{2+}$ per gram of $\mathrm{MA}$ at a dosage of $750 \mathrm{ppm}$, with a corresponding efficiency of the treatment equal to $40 \%$. Increasing the dosage of the MA to $1000 \mathrm{ppm}$ led to an enhancement of efficiency of 3\%, while the adsorption capacity decreased to $150 \mathrm{mg}$ of $\mathrm{Cu}^{2+}$ per gram of MA (18\% lower). Increasing the dosage of the MA would raise the number of available adsorption sites, leading to a significant enhancement of the removal efficiency. Over a threshold dosage, the adsorption capacity decreased and the efficiency enhancement became slower. This behavior could be due to a high concentration of MA in water that led to an aggregation of particles during the mixing process. Despite the fact that the concentration of MA in water increased with the higher dosage, the total surface available for the adsorption decreased due to the formation of aggregates of higher dimension, with a consequent reduction in the adsorption capacity [32-34]. This explanation may be supported by the fact that MA with $10 \% w / w$ of coating presented the decay of adsorption capacity at higher dosage due to the higher stability towards aggregation. Another explanation, reported in other studies, is attributed to induced metal ions desorption from the particles' surface at higher dosage [35].

In the FT-IR spectrum of the MA after the adsorption of copper (Figure 8), the characteristic peaks of the O-H of carboxylic groups that are present between 3000 and $3500 \mathrm{~cm}^{-1}$ disappeared, confirming that the metal ions are adsorbed on the MA through these moieties.

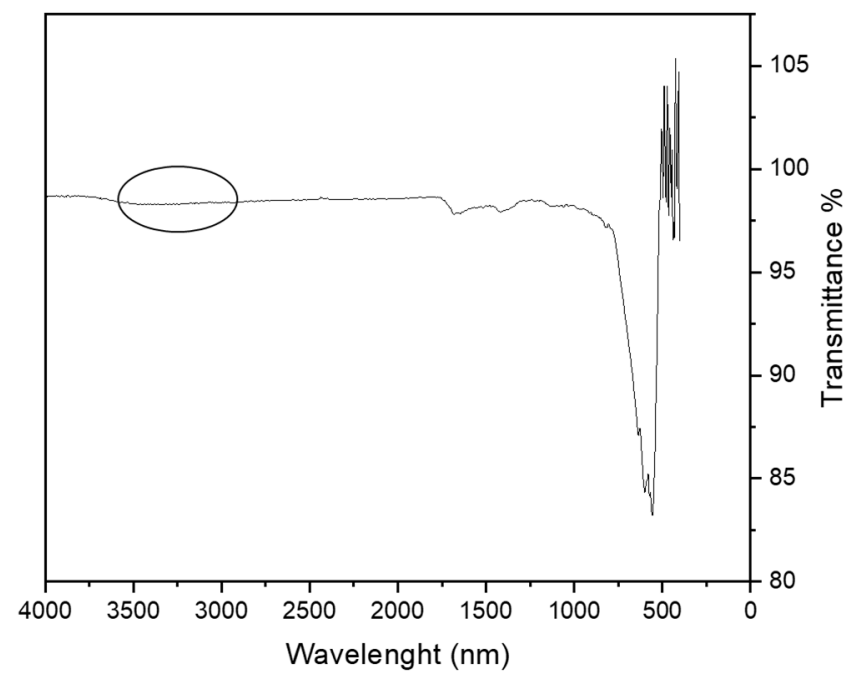

Figure 8. FTIR spectrum of the MA with $10 \%$ of coating after the adsorption of copper ions.

\subsubsection{Double-Ion Adsorption}

A short contact time to reach the adsorbent equilibrium was observed also in the experiments conducted on sample 2 , which contained copper and zinc as pollutants. The experiments were carried out as previously described, using a dosage of $1000 \mathrm{ppm}$. Figure 9 shows that the maximum adsorption capacity was reached within $10 \mathrm{~min}$ and then the value remained stable at longer contact times. These experiments confirmed that the efficiency in the removal of metal ions is higher for the MA with a higher content of succinic acid. The values of Qmax are higher in the case of experiments done with MA with $10 \% w / w$ of coating (Figure $9 \mathrm{~b}$ ) in comparison with the ones obtained with MA with $5 \% w / w$ of coating (Figure 9a). Of note, a difference in the efficiency was found for the two types of metal ions. The maximum adsorption capacity in the removal of copper was higher than the one of zinc in both the cases of using MA with $10 \% w / w$ and $5 \% w / w$ of the coating: 
$62 \mathrm{mg}$ of $\mathrm{Cu}^{2+}$ per gram of MA vs. $53 \mathrm{mg}$ of $\mathrm{Zn}^{2+}$ per gram of MA using MA with $10 \%$ $w / w$ of coating, and $37 \mathrm{mg}$ of $\mathrm{Cu}^{2+}$ per gram of MA vs. $33 \mathrm{mg}$ of $\mathrm{Zn}^{2+}$ per gram of MA using MA with $5 \% w / w$ of the coating. This behavior was attributed to the dependence of the adsorption mechanism on the electrostatic interactions and the difference in the size of hydrated ionic radii (zinc $4.35 \AA$ > copper $4.19 \AA$, Qzinc < Qcopper). The higher the hydrated ionic radius, the greater the distance from the adsorption negatively charged sites on the MA, resulting in weaker adsorption and thus a lower adsorption capacity $[28,36,37]$. The effect of dosage on the adsorption capacity versus the efficiency of the treatment was also studied for sample 2 wastewater. Figure 8 shows the dependence of the adsorption capacity vs. efficiency at different MA dosages. The general trend observed in the treatment of wastewater containing both metal ions was in line with the one observed in the case of wastewater polluted with a single metal ion (sample 1). The adsorption capacity remained constant while the efficiency increased linearly by increasing the dosage of the MA. After a certain dosage, $500 \mathrm{ppm}$ for the experiment conducted with the MA with $5 \% w / w$ of coating (Figure 10a), and $750 \mathrm{ppm}$ for the experiment conducted with the MA with $10 \% w / w$ of coating (Figure 10b), a decrease in the adsorbent capacity was observed while the efficiency of the treatment rose at a slower rate.

a)

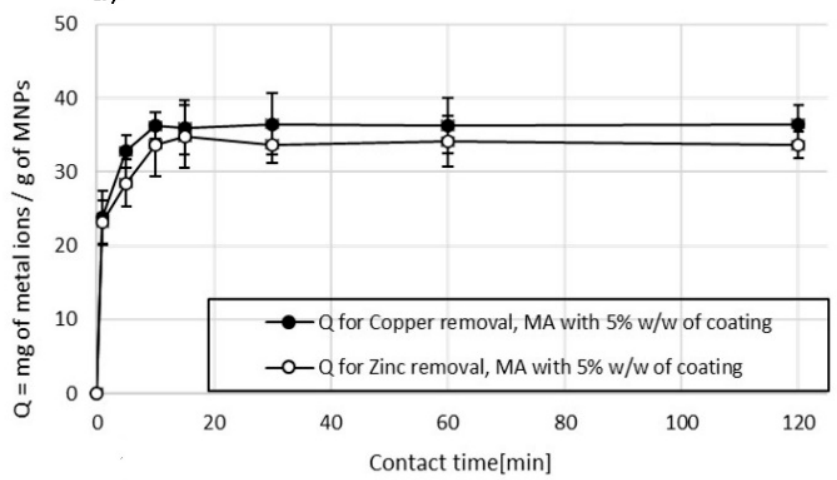

b)

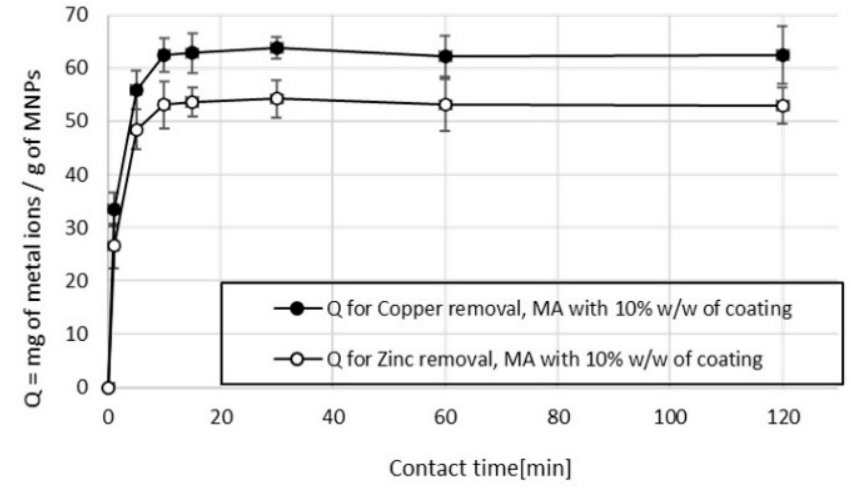

Figure 9. Effect of contact time on the adsorption capacity in the removal of $\mathrm{Cu}^{2+}$ and $\mathrm{Zn}^{2+}$. (a) MA with $5 \% w / w$ coating and (b) MA with $10 \% w / w$ coating, pH 7.2. 

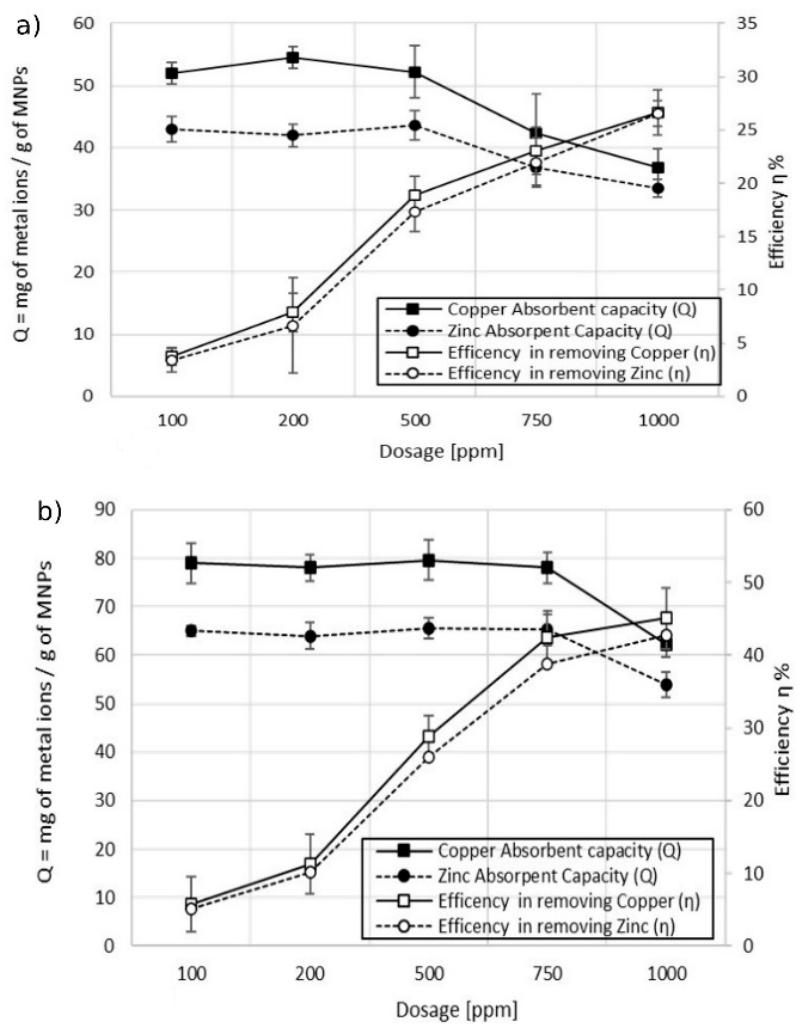

Figure 10. Effect of contact time on the adsorption capacity in the removal of $\mathrm{Cu}^{2+}$ and $\mathrm{Zn}^{2+}$. (a) MA with $5 \% w / w$ coating and (b) MA with $10 \% w / w$ coating, $\mathrm{pH} 7.2$.

\subsection{Adsorption Isotherm}

Langmuir and Freundlich's adsorption isotherm models were used to understand the adsorption mechanism of the $\mathrm{Cu}^{2+}$ and $\mathrm{Zn}^{2+}$ ions on the functionalized MA. This analysis is crucial to understand how the adsorbed compounds interact with the surface of the MA.

Langmuir's model assumes that the adsorption process takes place at specific homogeneous sites within the adsorbent and all sorption sites are identical and energetically equivalent. According to Langmuir's model, once the sites of the adsorbent are filled, there is no possibility of further adsorption. The surface of the adsorbent reaches a saturation point corresponding to a maximum adsorption capacity $\mathrm{Q}_{\max }$. This model is commonly used in monolayer adsorption processes. The linear form of the Langmuir isotherm is expressed by the following equation:

$$
1 / \mathrm{Q}_{\mathrm{e}}=1 / \mathrm{Q}_{\max }+1\left(\mathrm{~K}_{\mathrm{L}} \mathrm{Q}_{\max } \mathrm{C}_{\mathrm{e}}\right)^{-1}
$$

where $\mathrm{Q}_{\max }$ is the maximum amount of adsorption with complete monolayer coverage on the adsorbent surface $\left(\mathrm{mg} \mathrm{g}^{-1}\right), \mathrm{K}_{\mathrm{L}}$ is the Langmuir constant related to the energy of adsorption $\left(\mathrm{L} \mathrm{mg}^{-1}\right)$, and $\mathrm{Q}_{\mathrm{e}}$ and $\mathrm{C}_{\mathrm{e}} \mathrm{Q}$ indicate, respectively, the adsorption capacity at equilibrium and the equilibrium concentration. The Langmuir constants $\mathrm{K}_{\mathrm{L}}$ and $\mathrm{Q}_{\max }$ were calculated from the linear plot of $1 / C_{e}$ versus $1 / Q_{e}$. The $K_{L}$ parameter is used for predicting the affinity between the sorbate species and sorbent compound, thus when adsorption is favorable or unfavorable, through a dimensionless constant called separation factor or equilibrium parameter $\left(\mathrm{R}_{\mathrm{L}}\right)$.

$$
\mathrm{R}_{\mathrm{L}}=1 /\left(1+\mathrm{K}_{\mathrm{L}} \mathrm{C}_{0}\right)
$$

where $\mathrm{C}_{0}\left(\mathrm{mg} \mathrm{L}^{-1}\right)$ is the initial concentration of the ions. The value of $\mathrm{R}_{\mathrm{L}}$ indicates if the absorption process is irreversible $\left(\mathrm{R}_{\mathrm{L}}=0\right)$, linear $\left(\mathrm{R}_{\mathrm{L}}=1\right)$, unfavorable $\left(\mathrm{R}_{\mathrm{L}}>1\right)$, or favorable $\left(0<\mathrm{R}_{\mathrm{L}}<1\right)$. 
The Freundlich isotherm is commonly used to describe heterogeneous systems and reversible adsorption, which is not always related to monolayer formations. It gives information about the heterogeneity of the adsorbent surface. The linear form of the Freundlich adsorption isotherm is expressed as:

$$
\log \left(\mathrm{Q}_{\mathrm{e}}\right)=\log \left(\mathrm{K}_{\mathrm{F}}\right)+1 / \mathrm{n} \log \left(\mathrm{C}_{\mathrm{e}}\right)
$$

where $\mathrm{K}_{\mathrm{F}}$ is the Freundlich constant and it indicates the adsorption capacity, $\mathrm{n}$ is an empirical parameter related to the intensity of adsorption. The value of $n$ is correlated to the heterogeneity of the adsorbent and, for favorable adsorption processes, the value of $\mathrm{n}$ is comprised in the range of $1-10$. The value of $K_{\mathrm{F}}$ and $\mathrm{n}$ were calculated from the intercept and slope of the linear plot of $\log C_{e}$ vs. $\ln Q_{e}$. Figures 11-14 represent plots of the experimental data based on the Langmuir and Freundlich isotherm models for all the series of experiments performed in this work.
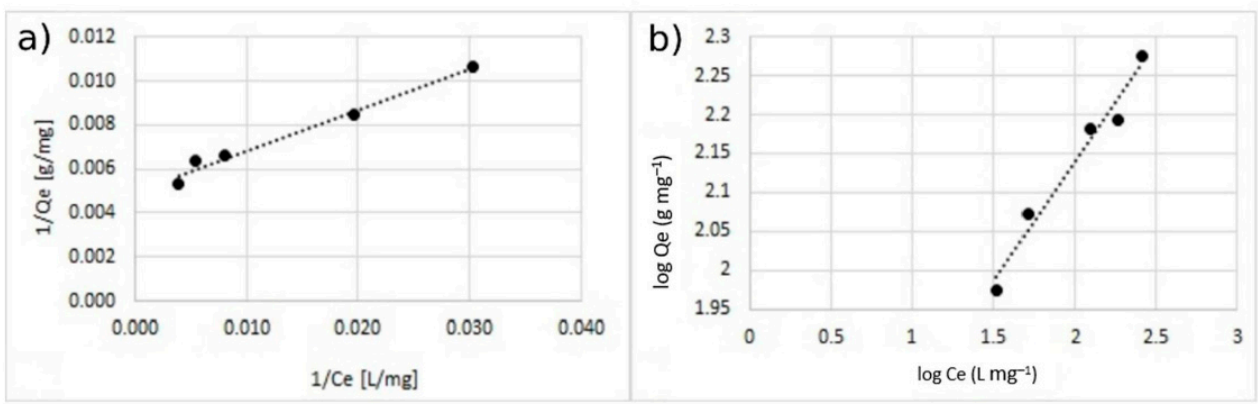

Figure 11. Adsorption isotherm for adsorption of $\mathrm{Cu}^{2+}$ using MA with $10 \% w / w$ of the coating. (a) Langmuir model and (b) Freundlich model.
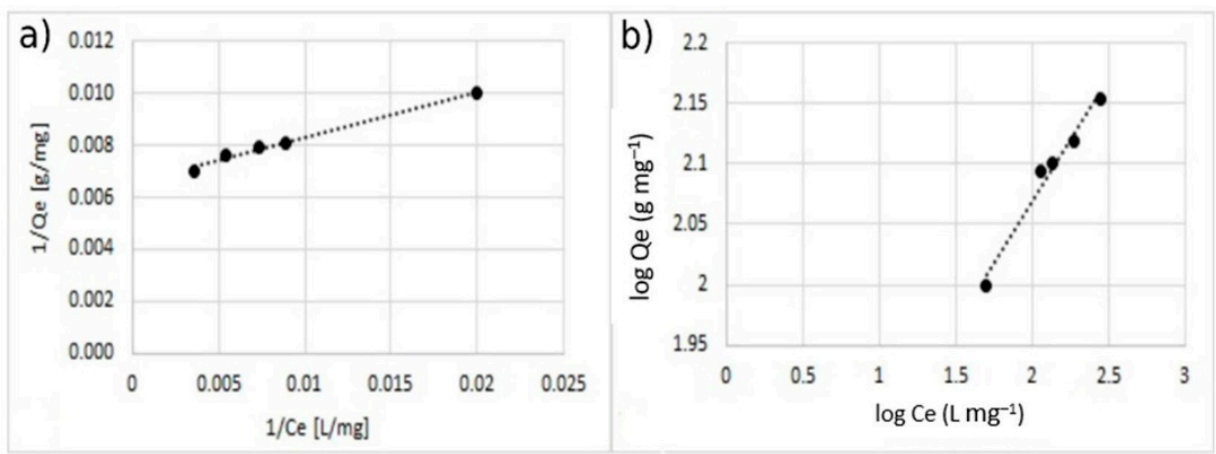

Figure 12. Adsorption isotherm for adsorption of $\mathrm{Cu}^{2+}$ using MA with $5 \% w / w$ of the coating. (a) Langmuir model and (b) Freundlich model.
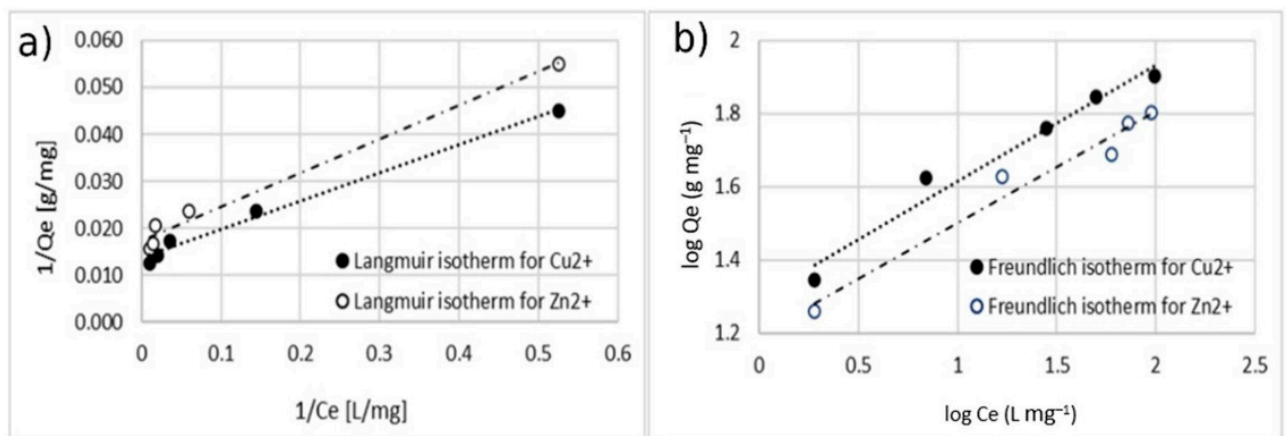

Figure 13. Adsorption isotherm for adsorption of $\mathrm{Cu}^{2+}$ and $\mathrm{Zn}^{2+}$ using MA with $10 \% w / w$ of coating. (a) Langmuir model and (b) Freundlich model. 

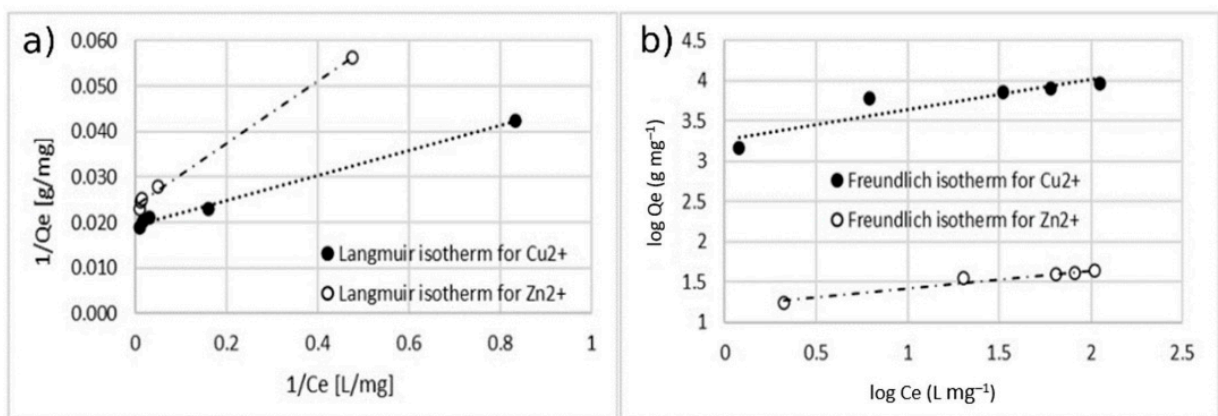

Figure 14. Adsorption isotherm for adsorption of $\mathrm{Cu}^{2+}$ and $\mathrm{Zn}^{2+}$ using MA with $5 \% w / w$ of coating. (a) Langmuir model and (b) Freundlich model.

Tables 1 and 2 report all the models' parameters obtained by fitting the experimental data within both the isotherm models. Table 1 collects the results belonging to single-ion adsorption experiments; Table 2 collects the results regarding the double-ion adsorption experiment.

Table 1. Isotherm constants for the adsorption of $\mathrm{Cu}^{2+}$.

\begin{tabular}{|c|c|c|c|c|c|c|c|}
\hline \multirow{2}{*}{$\%$ Coating $w / w$} & \multicolumn{4}{|c|}{ Langmuir Model } & \multicolumn{3}{|c|}{ Freundlich Model } \\
\hline & $Q_{\max }\left(\mathrm{mg} \mathrm{g}^{-1}\right)$ & $K_{L}\left(L^{-1}\right)$ & $\mathrm{R}_{\mathrm{L}}$ Range & $\mathbf{r}^{2}$ & $\mathbf{n}$ & $\mathbf{K}_{\mathbf{F}}$ & $\mathbf{r}^{2}$ \\
\hline 5 & 148.5 & 0.039 & $0.068-0.205$ & 0.991 & 4.95 & 46.2 & 0.9681 \\
\hline 10 & 192.3 & 0.028 & $0.093-0.311$ & 0.982 & 3.24 & 33.34 & 0.9612 \\
\hline
\end{tabular}

Table 2. Isotherm constants for the adsorption of $\mathrm{Cu}^{2+}$ and $\mathrm{Zn}^{2+}$.

\begin{tabular}{|c|c|c|c|c|c|c|c|c|}
\hline \multirow{2}{*}{$\%$ Coating $w / w$} & \multicolumn{5}{|c|}{ Langmuir Model } & \multicolumn{3}{|c|}{ Freundlich Model } \\
\hline & ion & $Q_{\max }\left(\mathrm{mg} \mathrm{g}^{-1}\right)$ & $K_{L}\left(L^{-1}\right)$ & $\mathrm{R}_{\mathrm{L}}$ Range & $\mathbf{r}^{2}$ & $\mathrm{n}$ & $\mathbf{K}_{\mathbf{F}}$ & $\mathbf{r}^{2}$ \\
\hline \multirow{2}{*}{5} & copper & 51.82 & 0.699 & $0.01-0.099$ & 0.994 & 6.131 & 2.241 & 0.841 \\
\hline & zinc & 42.19 & 0.346 & $0.022-0.207$ & 0.996 & 4.524 & 15.958 & 0.951 \\
\hline \multirow{2}{*}{10} & copper & 74.07 & 0.224 & $0.031-0.255$ & 0.989 & 3.161 & 19.961 & 0.968 \\
\hline & zinc & 58.14 & 0.239 & $0.032-0.278$ & 0.9853 & 3.262 & 15.653 & 0.961 \\
\hline
\end{tabular}

The comparison between the values of the correlation coefficient $\left(\mathrm{r}^{2}\right)$ of the linearized isotherm models suggested that the Langmuir model fitted the experimental data better for both the cases of single- and double-ion adsorption. The value of the $\mathrm{Q}_{\max }$ calculated with Langmuir model was similar to the one obtained with experimental data. The value of $\mathrm{K}_{\mathrm{L}}$ was in the range of $0-1$, indicating that the adsorption of $\mathrm{Cu}^{2+}$ and $\mathrm{Zn}^{2+}$ on the surface of coated MA was favorable. This is also confirmed by the n-parameter, calculated by using the Freundlich model which was in the range of $0-10$.

\subsection{Kinetic Studies}

The adsorption kinetics of metal ions on the coated MA were analyzed by four kinetic models: Lagergren pseudo-first-order kinetic (Equation (6)), pseudo-second-order kinetic (Equation (7)), Elovich model (Equation (8)), and the Weber and Morris model (Equation (9)).

$$
\begin{gathered}
\operatorname{Ln}\left(Q_{e}-Q_{t}\right)=\ln \left(Q_{e}\right)-K_{1} t \\
t / Q_{t}=1\left(K_{2} Q_{e}{ }^{2}\right)^{-1}+t / Q_{e}
\end{gathered}
$$

where $\mathrm{Q}_{\mathrm{t}}\left(\mathrm{mg} \mathrm{g}^{-1}\right)$ is the adsorption at time $\mathrm{t}(\mathrm{min}) ; \mathrm{Q}_{\mathrm{e}}\left(\mathrm{mg} \mathrm{g}^{-1}\right)$ indicates the adsorption capacity at adsorption equilibrium; and $\mathrm{K}_{1}\left(\mathrm{~min}^{-1}\right)$ and $\mathrm{K}_{2}\left(\mathrm{~g} \mathrm{mg}^{-1} \mathrm{~min}^{-1}\right)$ represent the kinetic constants for the pseudo-first-order and the pseudo-second-order models, 
respectively. The Elovich model (Equation (8)) is used to describe the adsorption process on adsorbent material with a heterogeneous surface. From its linear model, is it possible to calculate the initial adsorption rate $\alpha\left(\mathrm{mg} \mathrm{g}^{-1} \mathrm{~min}^{-2}\right)$ and the desorption constant $\beta$ $\left(\mathrm{g} \mathrm{mg}^{-1} \mathrm{~min}^{-1}\right.$ ).

$$
\mathrm{Q}_{\mathrm{t}}=1 / \beta \ln (\alpha \beta)+1 / \beta \ln (\mathrm{t})
$$

An intra-particle diffusion mechanism was explored by using the Weber and Morris model (Equation (9)).

$$
3 Q_{t}=\left(K_{\text {intra }} t^{1 / 2}\right)+C
$$

where $K_{\text {intra }}$ is the intra-particle diffusion rate constant $\left(\mathrm{mg} \mathrm{g}^{-1} \mathrm{~min}^{-1 / 2}\right)$ and $\mathrm{C}$ is a constant related to the thickness of the boundary layer $\left(\mathrm{mg} \mathrm{g}^{-1}\right)$. Figures 15-17 represent plots of the experimental data based on the four kinetic models adopted.
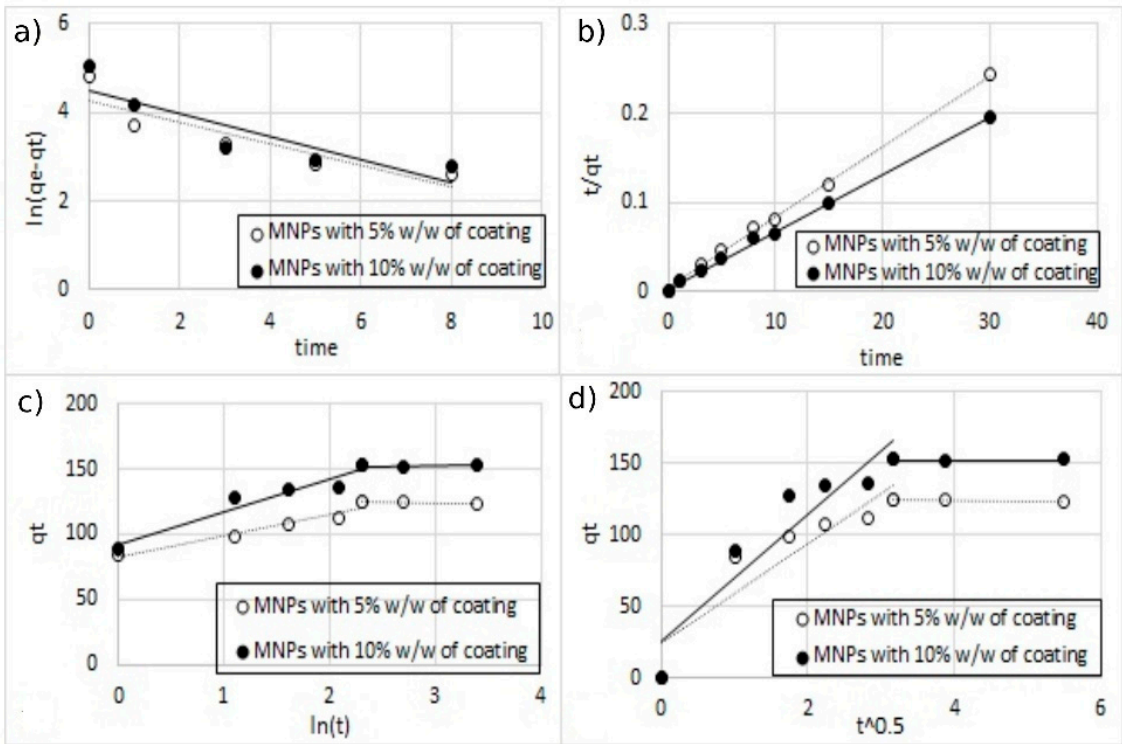

Figure 15. The fitting of different kinetic models for single-ion adsorption $\left(\mathrm{Cu}^{2+}\right)$ onto MA functionalized with $5 \%$ and $10 \% w / w$ of coating, (a) pseudo-first-order, (b) pseudo-second-order, (c) Elovich model, and (d) intra-particle diffusion model.
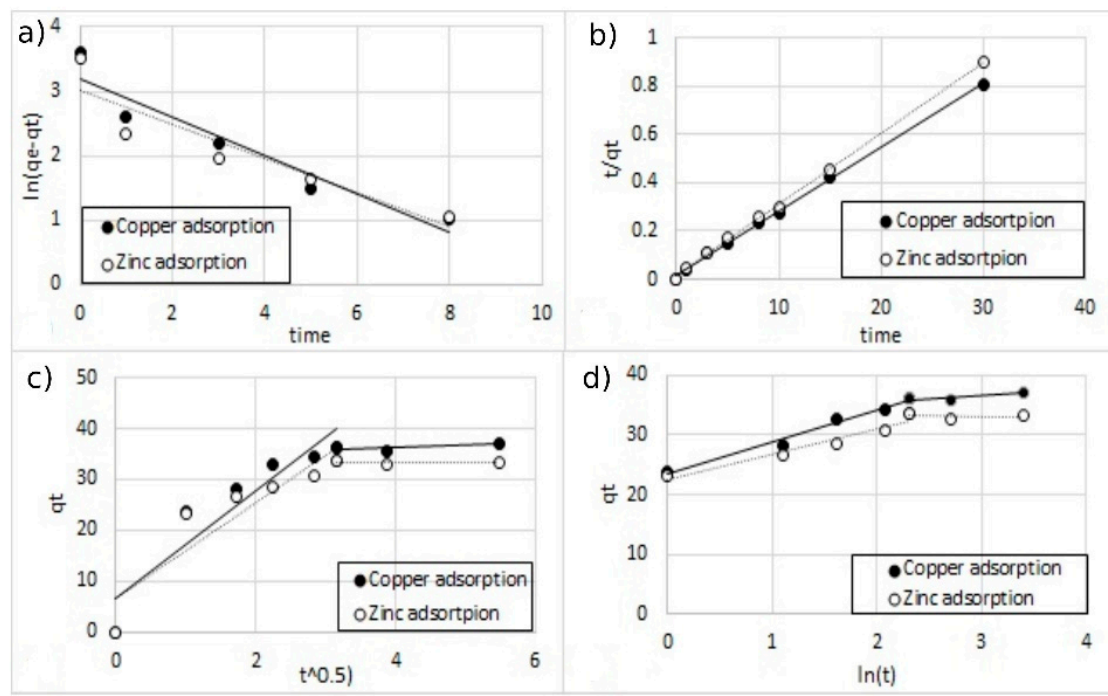

Figure 16. The fitting of different kinetic models for double-ion adsorption $\left(\mathrm{Cu}^{2+}\right.$ and $\left.\mathrm{Zn}^{2+}\right)$ onto MA functionalized with 5\% of coating, (a) pseudo-first-order, (b) pseudo-second-order, (c) Elovich model, and (d) intra-particle diffusion model. 

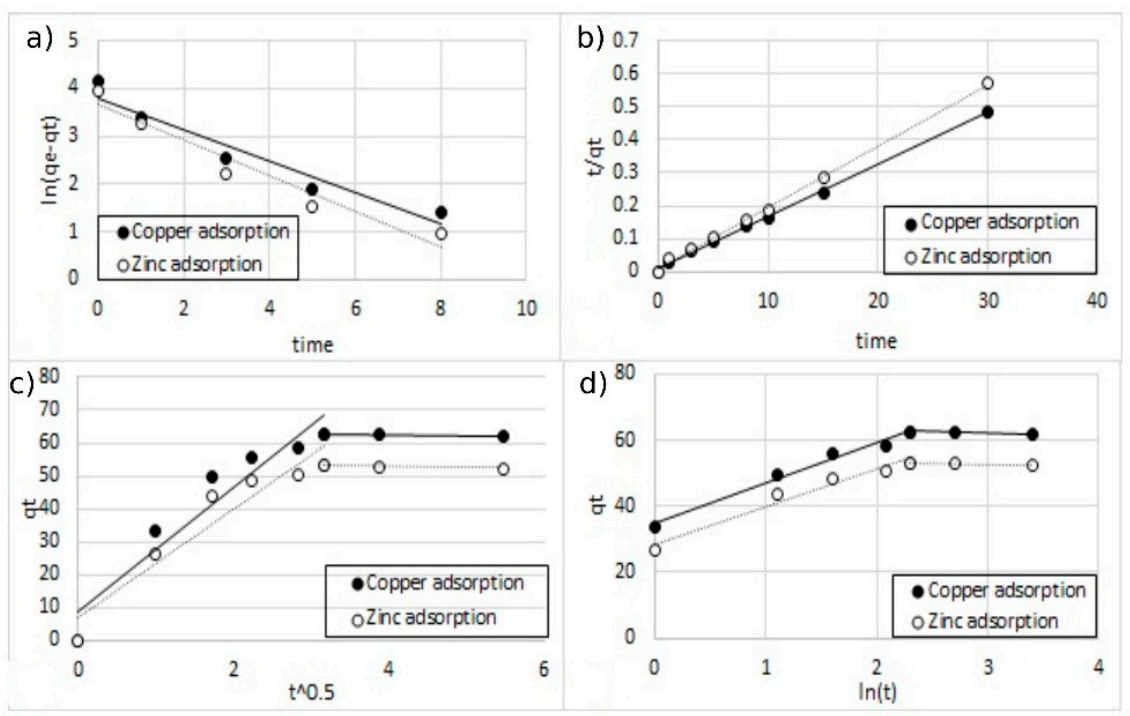

Figure 17. The fitting of different kinetic models for double-ion adsorption $\left(\mathrm{Cu}^{2+}\right.$ and $\left.\mathrm{Zn}^{2+}\right)$ onto MA functionalized with $10 \%$ of coating, (a) pseudo-first-order, (b) pseudo-second-order, (c) Elovich model, and (d) intra-particle diffusion model.

All the parameters of the different models calculated from the regressions are reported in Table 3. For all the regression, the sum of error squared (SSE) between the predicted values and the experimental data was measured. The best results in terms of higher correlation coefficients $\left(\mathrm{R}^{2}\right)$ with low SSE values were obtained, with the pseudo-second-order kinetic model indicating that the adsorption mechanism is dependent on the adsorbate and the adsorbent $[12,38]$. This result was indeed expected since the adsorption model is based on the interaction between the negative charges present on the surface of the MA and the positive charges of metal ions.

Table 3. Kinetic parameters of the different models for single-ion and double-ion adsorption onto functionalized MA.

\begin{tabular}{|c|c|c|c|c|c|c|}
\hline \multirow{3}{*}{$\begin{array}{c}\text { Kinetic Parameters } \\
\text { Coating }\end{array}$} & \multicolumn{2}{|c|}{ Single-Ion Adsorption } & \multicolumn{4}{|c|}{ Double-Ion Adsorption } \\
\hline & $5 \% w / w$ & $10 \% w / w$ & \multicolumn{2}{|c|}{$5 \% w / w$} & \multicolumn{2}{|c|}{$10 \% w / w$} \\
\hline & \multicolumn{2}{|c|}{ Copper } & Copper & Zinc & Copper & Zinc \\
\hline $\mathrm{Q}_{\mathrm{e}}(\exp )\left(\mathrm{mg} \mathrm{L}^{-1}\right)$ & 125.2 & 152.8 & 37.2 & 33.7 & 62.6 & 53.1 \\
\hline \multicolumn{7}{|l|}{ wPseudo-first order model } \\
\hline $\mathrm{Q}_{\mathrm{e}}($ calc $)\left(\mathrm{mg} \mathrm{L}^{-1}\right)$ & 72.588 & 91.049 & 24.501 & 20.166 & 44.768 & 39.064 \\
\hline $\mathrm{K}_{1}\left(\mathrm{~min}^{-1}\right)$ & 0.247 & 0.261 & 0.298 & 0.263 & 0.331 & 0.374 \\
\hline$R^{2}$ & 0.805 & 0.781 & 0.907 & 0.849 & 0.936 & 0.944 \\
\hline SSE & 53.733 & 62.255 & 12.710 & 13.752 & 17.920 & 13.813 \\
\hline \multicolumn{7}{|l|}{ Pseudo-second order model } \\
\hline $\mathrm{Q}_{\mathrm{e}}($ calc $)\left(\mathrm{mg} \mathrm{L}^{-1}\right)$ & 126.582 & 156.250 & 37.736 & 33.784 & 63.291 & 53.476 \\
\hline $\mathrm{K}_{2}\left(\mathrm{mg} \mathrm{L}^{-1}\right)$ & 0.016 & 0.011 & 0.044 & 0.059 & 0.032 & 0.042 \\
\hline $\mathrm{R}^{2}$ & 0.998 & 0.986 & 0.991 & 0.989 & 0.992 & 0.988 \\
\hline SSE & 5.391 & 6.076 & 1.244 & 1.335 & 3.661 & 3.900 \\
\hline \multicolumn{7}{|l|}{ Intra } \\
\hline $\mathrm{Q}_{\mathrm{e}}($ calc $)\left(\mathrm{mg} \mathrm{L}^{-1}\right)$ & 127.610 & 152.190 & 34.209 & 33.644 & 63.645 & 54.068 \\
\hline Kintra $\left(\mathrm{mg} \mathrm{g}^{-1} \min ^{-1 / 2}\right)$ & 34.966 & 44.399 & 10.585 & 9.431 & 19.008 & 16.506 \\
\hline $\mathrm{C}$ & 24.269 & 25.640 & 6.567 & 6.575 & 8.649 & 6.936 \\
\hline $\mathrm{R}^{2}$ & 0.876 & 0.546 & 0.782 & 0.543 & 0.906 & 0.941 \\
\hline SSE & 14.535 & 16.440 & 3.941 & 3.919 & 5.599 & 5.260 \\
\hline \multicolumn{7}{|l|}{ Elovich } \\
\hline $\mathrm{Q}_{\mathrm{e}}($ calc $)\left(\mathrm{mg} \mathrm{L}^{-1}\right)$ & 128.850 & 152.270 & 33.436 & 33.960 & 64.189 & 54.612 \\
\hline alpha $\left(\mathrm{mg} \mathrm{g}^{-1} \min ^{-1}\right)$ & 2975.211 & 1025.352 & 402.383 & 879.825 & 205.754 & 141.845 \\
\hline beta $\left(\mathrm{g} \mathrm{mg}^{-1} \mathrm{~min}^{-1}\right)$ & 0.063 & 0.040 & 0.184 & 0.237 & 0.081 & 0.089 \\
\hline $\mathrm{R}^{2}$ & 0.937 & 0.579 & 0.804 & 0.623 & 0.967 & 0.969 \\
\hline SSE & 2.82 & 4.812 & 0.597 & 0.763 & 1.129 & 1.668 \\
\hline
\end{tabular}




\subsection{Evaluation of the Electrochemical Activity}

Electrochemical characterization tests were conducted to observe the variation in the electrochemical activity of the magnetite particles with absorbed metal cations. These preliminary tests were carried out on the hypothesis of desorbing the metal ion from the surface of the MA, applying a polarization. The electrochemical activity of the functionalized particles can be observed from the CV curves (Figure 18). The presence of redox peaks indicated the coated particles to be active, i.e., taking part in the electrochemical reactions. At high cathodic bias, the oxide surface may be reduced to metallic iron, as indicated by the broad cathodic peak at about $-1 \mathrm{~V}$ vs. $\mathrm{Ag} / \mathrm{AgCl}$. The position of the oxidation peak in the backward scan, associated with the oxidation of the surface metallic iron back into magnetite, suggested good reversibility of the reaction. The results suggested the coated-MA to be electrochemically active.
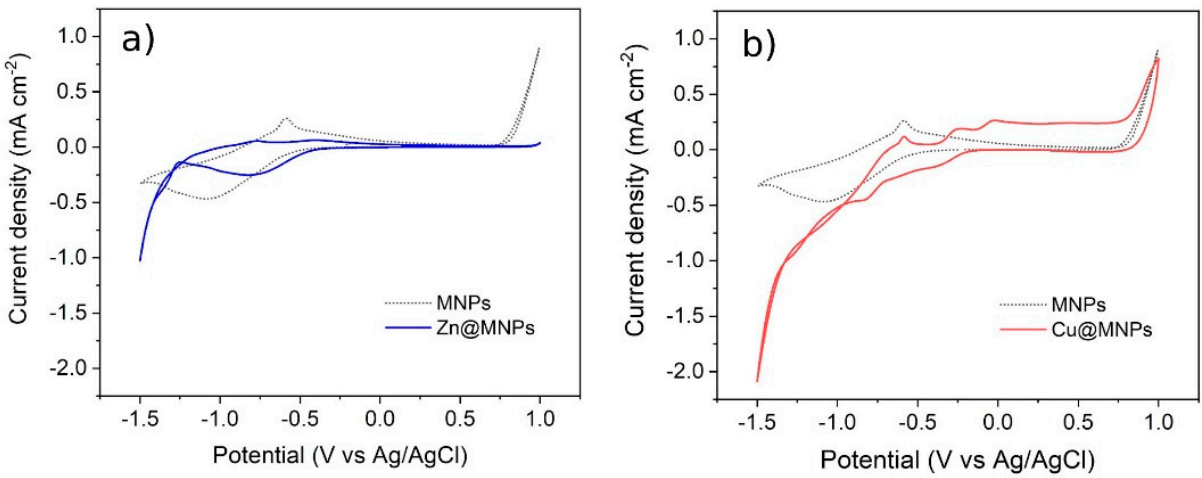

Figure 18. Cyclic voltammetry on MA used in the treatment of wastewater samples, (a) $\mathrm{Zn}^{2+}$ absorbed MA. (b) $\mathrm{Cu}^{2+}$-absorbed MA. (Dotted curve: functionalized MA with no ions absorbed).

Eventally, the tests were carried out on the magnetite aggregates after the absorption of metallic cations, i.e., $\mathrm{Zn}$ and $\mathrm{Cu}$. The electrochemical activity of the Zn@MA signicantly changed with respect to the reference sample. In particular, even if the redox reactions related to $\mathrm{Fe}_{3} \mathrm{O}_{4}$ were still present, the peaks associated with zinc reduction $(-1.3 \mathrm{~V}$ vs. $\mathrm{Ag} / \mathrm{AgCl})$ and oxidation $(-0.8 \mathrm{~V}$ vs. $\mathrm{Ag} / \mathrm{AgCl})$ reactions were observed. In analogy to the zinc case, the magnetite particles were immersed in a solution containing copper ions, to promote their absorption. The Cu@MA particles showed additional redox peaks with respect to the reference sample. In particular, the anodic peaks close to $0 \mathrm{~V}$ vs. $\mathrm{Ag} / \mathrm{AgCl}$ may be ascribed to the oxidation of copper, suggesting its reduction during the cathodic scan. These results suggest that ions absorbed on the MA effectively interact electrochemically with the electrode surface, suggesting the possibility to recover the absorbed metal cations by applying a polarization. To verify the reduction of the absorbed metals on the electrode surface, allowing the recovery of this material through this method, further experiments and characterization need to be performed.

\section{Conclusions}

In this work, aggregates of $\mathrm{Fe}_{3} \mathrm{O}_{4}$ nanoparticles functionalized with succinic acid were synthesized by a single-step co-precipitation method. Their capacity in adsorbing transition metals was proved by treating two samples of industrial wastewater contaminated with transition metals, $\mathrm{Cu}^{2+}$ and $\mathrm{Zn}^{2+}$. Adsorption measurements showed that MA need a short contact time to reach the equilibrium, which was reached within $10 \mathrm{~min}$ in all experiments. The maximum adsorption capacity was $188 \mathrm{mg}$ of $\mathrm{Cu}^{2+}$ per gram of MA in the case of wastewater contaminated with a single ion, and $62 \mathrm{mg}$ of $\mathrm{Cu}^{2+}$ per gram of MA and $53 \mathrm{mg}$ of $\mathrm{Zn}^{2+}$ per gram of MA in the case of wastewater contaminated with both ions. The percentage of MA coating was $10 \% w / w$ in both cases. The adsorption mechanism was driven mainly by electrostatic attraction between metal ions and MA and this process was influenced by the hydrated ionic radius of the metal. From the two 
adsorption isotherm models used here, the Langmuir isotherm adsorption model better fitted the adsorption data. The adsorption process follows a pseudo-second-order kinetic mechanism. In conclusion, it was demonstrated that MA with a magnetite core and an outer coating made by succinic acid could be a promising material for efficient and fast removal and recovery of transition metals from wastewater. Moreover, the electrochemical activity of the MA was proved, showing that an electrochemical process for recycling the MA and extracting the transition metals is worth being investigated.

Author Contributions: Conceptualization, L.M.; methodology, R.P., G.P. and A.A.; software, J.I. and C.K.; validation, formal analysis, investigation R.P., C.J.P., G.P. and A.A.; resources, L.M.; data curation R.P., G.P., J.I., C.K. and A.A.; writing-original draft preparation, R.P., C.K., G.P.; writing-review and editing, C.K., G.P.; visualization, L.M.; supervision, L.M.; project administration, L.M.; funding acquisition, L.M. All authors have read and agreed to the published version of the manuscript.

Funding: This research was funded by European Union's Horizon 2020 research and innovation programme under Grant Agreement No. 821431.

Data Availability Statement: The data presented in this study are available on request from the corresponding author. The data are not publicly available due to privacy issues of the involved company.

Acknowledgments: We thank Captive Systems srl for providing the materials used for the experiments and Gaser Group for providing the samples used in the experiments.

Conflicts of Interest: The authors declare no conflict of interest. The funders had no role in the design of the study; in the collection, analyses, or interpretation of data; in the writing of the manuscript, or in the decision to publish the results.

\section{References}

1. Al-Saydeh, S.A.; El-Naas, M.; Zaidi, S.J. Copper removal from industrial wastewater: A comprehensive review. J. Ind. Eng. Chem. 2017, 56, 35-44. [CrossRef]

2. Arbabi, M.; Golshani, N. Removal of copper ions $\mathrm{Cu}$ (II) from industrial wastewater: A review of removal methods. Int. J. Epidemiol. Res. 2016, 3, 283-293.

3. Zhang, X.; Yang, F.; Ma, J.; Liang, P. Effective removal and selective capture of copper from salty solution in flow electrode capacitive deionization. Environ. Sci. Water Res. Technol. 2019, 6, 341-350. [CrossRef]

4. Gakwisiri, C.; Raut, N.; Al-Saadi, A.; Al-Aisri, S.; Al-Ajmi, A. A Critical Review of Removal of Zinc from Wastewater. Proc. World Congr. Eng. 2012, 1, 627-630.

5. Emadi, M.; Shams, E.; Amini, M.K. Removal of zinc from aqueous solutions by magnetite silica core-shell nanoparticles. J. Chem. 2013, 2013, 787682. [CrossRef]

6. Plum, L.M.; Rink, L.; Haase, H. The Essential Toxin: Impact of Zinc on Human Health. Int. J. Environ. Res. Public Health 2010, 7, 1342-1365. [CrossRef] [PubMed]

7. Şenel, S.; Uzun, L.; Kara, A.; Denizli, A. Heavy Metal Removal from Synthetic Solutions with Magnetic Beads Under Magnetic Field. J. Macromol. Sci. Part A 2008, 45, 635-642. [CrossRef]

8. Uzun, L.; Kara, A.; Osman, B.; Yılmaz, E.; Beşirli, N.; Denizli, A. Removal of heavy-metal ions by magnetic beads containing triazole chelating groups. J. Appl. Polym. Sci. 2009, 114, 2246-2253. [CrossRef]

9. Purnamawati, F.; Sembiring, R. Preparation of Magnetic Chitosan Beads for Heavy Metal Ions Removal from Water. IOP Conf. Ser. Earth Environ. Sci. 2019, 276, 012004. [CrossRef]

10. Rani, P.; Johar, R.; Jassal, P.S. Adsorption of nickel (II) ions from wastewater using glutaraldehyde cross-linked magnetic chitosan beads: Isotherm, kinetics and thermodynamics. Water Sci. Technol. 2020, 82, 2193-2202. [CrossRef] [PubMed]

11. Ahamad, T.; Naushad, M.; Eldesoky, G.E.; Alqadami, A.A.; Khan, A. Synthesis and characterization of egg-albumen-formaldehyde based magnetic polymeric resin (MPR): Highly efficient adsorbent for Cd(II) ion removal from aqueous medium. J. Mol. Liq. 2019, 286, 110951. [CrossRef]

12. Alqadami, A.A.; Naushad, M.; Abdalla, M.A.; Ahamad, T.; Alothman, Z.A.; Alshehri, S.M.; Ghfar, A.A. Efficient removal of toxic metal ions from wastewater using a recyclable nanocomposite: A study of adsorption parameters and interaction mechanism. J. Clean. Prod. 2017, 156, 426-436. [CrossRef]

13. Alqadami, A.A.; Naushad, M.; Alothman, Z.A.; Alsuhybani, M.; Algamdi, M. Excellent adsorptive performance of a new nanocomposite for removal of toxic $\mathrm{Pb}$ (II) from aqueous environment: Adsorption mechanism and modeling analysis. J. Hazard. Mater. 2020, 389, 121896. [CrossRef] [PubMed]

14. Naushad, M.; Alqadami, A.A.; Ahamad, T. Removal of Cd(II) ion from aqueous environment using triaminotriethoxysilane grafted oxidized activated carbon synthesized via activation and subsequent silanization. Environ. Technol. Innov. 2020, 18, 100686. [CrossRef] 
15. Alhumaimess, M.S.; Alsohaimi, I.H.; Alqadami, A.A.; Kamel, M.M.; Naushad, M.; Ahamad, T.; Alshammari, H. Synthesis of phosphorylated raw sawdust for the removal of toxic metal ions from aqueous medium: Adsorption mechanism for clean approach. J. Sol-Gel Sci. Technol. 2018, 89, 602-615. [CrossRef]

16. Khan, M.A.; Alqadami, A.A.; Wabaidur, S.M.; Siddiqui, M.R.; Jeon, B.-H.; Alshareef, S.A.; Alothman, Z.A.; Hamedelniel, A.E. Oil industry waste based non-magnetic and magnetic hydrochar to sequester potentially toxic post-transition metal ions from water. J. Hazard. Mater. 2020, 400, 123247. [CrossRef] [PubMed]

17. Singh, S.; Barick, K.; Bahadur, D. Surface engineered magnetic nanoparticles for removal of toxic metal ions and bacterial pathogens. J. Hazard. Mater. 2011, 192, 1539-1547. [CrossRef]

18. Sharma, M.; Kalita, P.; Senapati, K.K.; Garg, A. Study on Magnetic Materials for Removal of Water Pollutants. In Emerging Pollutants-Some Strategies for the Quality Preservation of Our Environment; IntechOpen Limite: London, UK, 2018. [CrossRef]

19. Luo, X.; Lei, X.; Cai, N.; Xie, X.; Xue, Y.; Yu, F. Removal of Heavy Metal Ions from Water by Magnetic Cellulose-Based Beads with Embedded Chemically Modified Magnetite Nanoparticles and Activated Carbon. ACS Sustain. Chem. Eng. 2016, 4, 3960-3969. [CrossRef]

20. Baresel, C.; Schaller, V.; Jonasson, C.; Johansson, C.; Bordes, R.; Chauhan, V.; Sugunan, A.; Sommertune, J.; Welling, S. Functionalized magnetic particles for water treatment. Heliyon 2019, 5, e02325. [CrossRef]

21. Baek, M.K.; Sung, T.I.; Cho, E.S.; Namkung, K.C.; Bae, D.J.; Park, I.H. Magnetic Separation for Contaminants in Wastewater Using Magnetic Micro Bead. IEEE Trans. Magn. 2012, 48, 3768-3771. [CrossRef]

22. Bora, T.; Dutta, J. Applications of Nanotechnology in Wastewater Treatment. Int. J. Innov. Emerg. Res. Eng. 2015, 2, 6. [CrossRef]

23. Ray, P.C.; Yu, H.; Fu, P.P. Toxicity and Environmental Risks of Nanomaterials: Challenges and Future Needs. J. Environ. Sci. Health Part C 2009, 27, 1-35. [CrossRef]

24. Moscatelli, D.; Masi, M.; Pesce, R.M. Amphiphilic Magnetic Nanoparticles and Aggregates to Remove Hydrocarbons and Metal Ions and Synthesis Thereof. U.S. Patent No. 10,418,159, 17 September 2019.

25. Prozorov, T.; Kataby, G.; Gedanken, A. Effect of surfactant concentration on the size of coated ferromagnetic nanoparticles. Thin Solid Films 1999, 340, 189-193. [CrossRef]

26. Puentes-Vara, L.A.; Gregorio-Jauregui, K.M.; Bolarín, A.M.; Navarro-Clemente, M.E.; Dorantes, H.J.; Corea, M. Effects of surfactant and polymerization method on the synthesis of magnetic colloidal polymeric nanoparticles. J. Nanoparticle Res. 2016, 18, 212. [CrossRef]

27. Huang, S.-H.; Chen, D.-H. Rapid removal of heavy metal cations and anions from aqueous solutions by an amino-functionalized magnetic nano-adsorbent. J. Hazard. Mater. 2009, 163, 174-179. [CrossRef] [PubMed]

28. Giraldo, L.; Erto, A.; Moreno-Piraján, J.C. Magnetite nanoparticles for removal of heavy metals from aqueous solutions: Synthesis and characterization. Adsorption 2013, 19, 465-474. [CrossRef]

29. Almomani, F.; Bhosale, R.; Khraisheh, M.; Kumar, A.; Almomani, T. Heavy metal ions removal from industrial wastewater using magnetic nanoparticles (MNP). Appl. Surf. Sci. 2020, 506, 144924. [CrossRef]

30. Ren, Y.; Abbood, H.A.; He, F.; Peng, H.; Huang, K. Magnetic EDTA-modified chitosan/SiO2/Fe3O4 adsorbent: Preparation, characterization, and application in heavy metal adsorption. Chem. Eng. J. 2013, 226, 300-311. [CrossRef]

31. Hao, Y.-M.; Man, C.; Hu, Z.-B. Effective removal of Cu (II) ions from aqueous solution by amino-functionalized magnetic nanoparticles. J. Hazard. Mater. 2010, 184, 392-399. [CrossRef]

32. Anwar, J.; Shafique, U.; Zaman, W.-U.; Salman, M.; Dar, A.; Anwar, S. Removal of Pb(II) and Cd(II) from water by adsorption on peels of banana. Bioresour. Technol. 2010, 101, 1752-1755. [CrossRef]

33. Karthikeyan, S.; Balasubramanian, R.; Iyer, C. Evaluation of the marine algae Ulva fasciata and Sargassum sp. for the biosorption of $\mathrm{Cu}$ (II) from aqueous solutions. Bioresour. Technol. 2007, 98, 452-455. [CrossRef] [PubMed]

34. Alsuhybani, M.; Alshahrani, A.; Algamdi, M.; Al-Kahtani, A.A.; Alqadami, A.A. Highly efficient removal of Pb(II) from aqueous systems using a new nanocomposite: Adsorption, isotherm, kinetic and mechanism studies. J. Mol. Liq. 2020, 301, 112393. [CrossRef]

35. Erentürk, S.; Malkoç, E. Removal of lead(II) by adsorption onto Viscum album L.: Effect of temperature and equilibrium isotherm analyses. Appl. Surf. Sci. 2007, 253, 4727-4733. [CrossRef]

36. Predescu, A.; Matei, E.; Berbecaru, A.; Vidu, R. Synthesis of Magnetic Nanoparticles for the Removal of Heavy Metal Ions from Wastewaters. ARA Annu. Congr. Proc. 2014. [CrossRef]

37. Mobasherpour, I.; Salahi, E.; Pazouki, M. Comparative of the removal of $\mathrm{Pb} 2+, \mathrm{Cd} 2+$ and Ni2+ by nano crystallite hydroxyapatite from aqueous solutions: Adsorption isotherm study. Arab. J. Chem. 2012, 5, 439-446. [CrossRef]

38. Wang, L.; Li, J.; Jiang, Q.; Zhao, L. Water-soluble Fe3O4 nanoparticles with high solubility for removal of heavy-metal ions from waste water. Dalton Trans. 2012, 41, 4544-4551. [CrossRef] [PubMed] 